\title{
Exploring the Factors that Affect Student Satisfaction through Using E-Learning in Malaysian Higher Education Institutions
}

\author{
Waleed Mugahed Al-rahmi* \\ Mohd Shahizan Othman \\ Lizawati Mi Yusuf
}

Department of Information System, Faculty of computing, Universiti Teknologi Malaysia, Johor Bahru, 81310, Malaysia

*Email: abumunir82@yahoo.com

\section{Doi:10.5901/mjss.2015.v6n4s1p299}

\begin{abstract}
In the e-learning literature, learning satisfaction with e-learning systems has been addressed. In the present study, a model and an instrument were developed to measure students' satisfaction with e-learning systems. The study provided a description of the procedures employed in survey conceptualization, items generation, data collection and validation of multiple-item scale. It also confirmed reliability and discriminant validity of data for analysis gathered from a sample comprising 268 respondents. The researcher made use of the structural equation modeling (SEM) method with the SmartPLS program to shed a light on the adoption process. The model comprises of factors including content of e-learning, interface of e-learning, personalization of elearning, community of e-learning, self-efficacy of e-learning, perceived usefulness, perceived ease of use and intention to use e-learning and their impact on the satisfaction of students. The model was developed on the basis of technology acceptance model (TAM) and the findings evidenced that the model is a robust theoretical tool employed to examine the acceptance of elearning among students.
\end{abstract}

Keywords: E-learning, Technology Acceptance Model, Students' Satisfaction and Higher Education.

\section{Introduction}

The electronic learning or e-learning refers to the action of knowledge acquisition through computer network on the basis of the environment. In the past ten years, e-learning has become a requirement in academic institutions in terms of its development and implementation. Owing to the advantages it offers to such institutions. In this regard, Rudy (2007) enumerated some of the advantages, which include lack of dependence on time limitations, the ability to ask questions freely and the access to materials at any place. However, e-learning is a relatively recent term employed to describe a learning form that can be carried out through websites. It is described as a tool of information delivery system that works through the Internet between to individuals and whether or not synchrony exists, depends on the time delivery or users' correspondence (Chou, 2003). Learners make use of network technologies in different countries to interact with other learners and instructors at various timings. In other words, e-learning is a new flexible method of learning (Lee et al., 2005). In the current times, majority of off-line universities have launched an e-learning plan while some have implemented it. Although e-learning growth has been monumental in terms of quantitative measures, there is an increasing concern for its quality assessment in the context of higher education (Lee, 2006). Added to this, there are specific barriers to the use of e-learning among universities and colleges (Leem \& Lim, 2007).

As a result, e-learning developers and delivers should understand students' perception and reaction to e-learning elements and how to effectively employ its system for learning enhancement (Koohang \& Durante, 2003). Moreover, shedding a light into the intentions and understanding of students of the factors influencing their satisfaction concerning e-learning can assist academic administrators and managers to develop mechanisms to attract students into employing e-learning (Grandon, Allshare \& Kwan, 2005). It is therefore required to carry out research dedicated to the factors influencing the satisfaction of students when it comes to e-learning. Majority of universities providing e-learning are faced with many challenges in realizing successful delivery, effectiveness and acceptance of their courses (Saade, 2003). The sole offering of any course and the replication of classroom experience online fall short of meeting the needs of students and may lead to their failure (Kilmurray, 2003). Another problem that arises in conjunction with online learning is the students' frustration of web-based education and this drives studies to research student-centered online education (Hara, 
2000). The increasing dependence on information systems and the rapid growth of new technologies that contribute to the learning environment necessitates the identification of significant factors relating to user technology acceptance (Yi \& Hwang, 2003). Thus, the primary objective of this study is to examine the factors affecting the satisfaction of students enrolled in Malaysian institutions of higher learning.

\section{E-learning in Malaysian Higher Education}

Strategies of e-learning were launched in Malaysian public universities in 1996, with the rapid economic and educational change in Malaysia. The country welcomed the new decade by unveiling Vision 2020. Such a move preceded the setting up of the Multimedia Super Corridor in 1996 and the privatization of tertiary education. This is followed by interrelated initiatives that transformed the educational sector of Malaysia. In this regard, Coffman (2008) assessed the implementation and success of e-learning strategies and analyzed e-learning policies adopted by tertiary institutions and the factors promoting the new method of lectures and tutorials delivery.

Considering the above study, the findings showed that a large proportion of Malaysian tertiary institutions (public and private have adopted e-learning strategies to offer academic programs via distance learning or to reinforce students who are studying full-time. E-learning is also described as online learning that is focused on course delivery to students with the help of computer-based medium. In fact, e-learning can be carried out in varying ways depending on the higher education institutions (HEls) requirements. Some of these institutions confine the delivery of their course materials through web while others possess an integrated framework for e-learning system to be utilized by full-time students as well as distance learning students. This has the tendency to offer the students with the mechanism to use technology in accessing class notes or relevant information, take tests, and interact among each other at any given time and place. Consequently, students attending universities are transforming into a diverse population requiring the proliferation of elearning based courses (Piccolo et al., 2001).

\section{Research Model and Hypothesis}

The present study combines the relevant factors namely content, interface, personalization, community, usefulness, selfefficacy and student's satisfaction into a single framework that can be tested and validated - such integration of elearning aspects was never conducted in prior studies. The main study hypotheses of the current study are as follows;

$\mathrm{H} 1$ : there's a significant relationship between content of e-learning and students' satisfaction.

$\mathrm{H} 2$ : there's a significant relationship between interface of e-learning and students' satisfaction.

H3: there's a significant relationship between personalization of e-learning and students' satisfaction.

$\mathrm{H} 4$ : there's a significant relationship between community of e-learning and students' satisfaction.

H5: there's a significant relationship between self-efficacy of e-learning and students' satisfaction.

H6: there's a significant relationship between perceived ease of use and intention to use.

$\mathrm{H7}$ : there's a significant relationship between perceived usefulness and intention to use.

H8: there's a significant relationship between perceived usefulness and perceived ease of use.

H9: there's a significant relationship between intention to use and students' satisfaction.

\section{Figure 1: The Research Model}

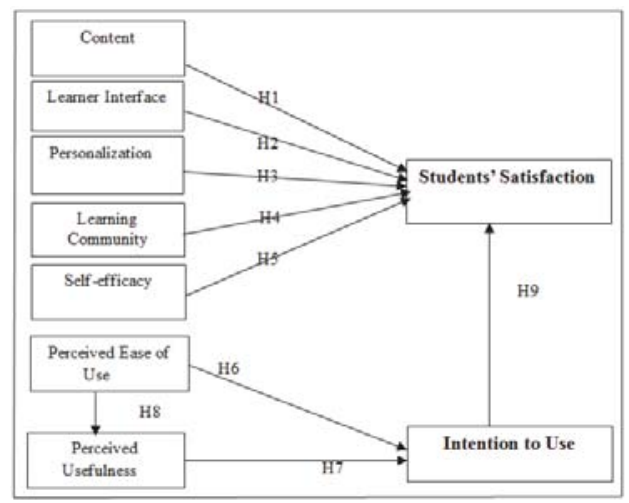




\subsection{Content of E-learning}

Prior studies are similar in that they all attempted to create an approach to the e-learning contexts where students perform various tasks depending on their initial knowledge and personal characteristics with the assessment being the driving impetus. Several studies were conducted to examining the major factors enabling the effectiveness of e-learning. For example, Liaw et al. (2007) combined different research findings concerning factors affecting e-learning effectiveness. The findings revealed that individual characteristics and contents are the two major components. A similar research was conducted by Hong (2002) who focused on e-learning effectives via the learner's behavior, teacher's personality, technology and contents. He found all the above factors to contribute to the effectiveness of e-learning. According to researchers, adopting varying approaches to e-learning will enhance the participation of students. Evidently, learner's behavioral intention in e-learning system use can be examined through two major factors namely students' satisfaction and perceived usefulness of e-learning system (Liaw, 2008).

\subsection{Learner Interface of E-learning}

Learner-interface can be improved through the provision of a suitable mechanism, simple and appropriate information which could motivate and at the same time assist students in their understanding and help them in their selection of information for acquisition (Ong \& Lai, 2006).

An ill-managed interface in the educational system can adversely impact the confidence level of the study, learning performance, and his moral and ethical values (Rovai, 2004). The interaction between the student and the interface were considered in prior research that attempted to improve education quality through e-learning (Chou, 2003). In sum, several studies have been dedicated to the interface design that is capable of interacting with different learners' personalities, and direct them into using and accepting the appropriate use of tool for different purposes. Added to this, the creation of a more structured screen layout and clarified instruction on e-learning tools will assist learners to effectively obtain and acquire the information, after which the learners will be convinced of the tools usefulness (Saade \& Otrakji, 2007).

\subsection{Personalization of E-learning}

As with the preceding factor, several studies have also shed a light on the personalization of the e-learning system and referred to it as a method to customize learning cases on the basis of the specific parameters. Personalization is attributed to different characteristics and requirements. For example, the fundamental knowledge, learning patterns and inspiration differ from one learner to another. These differences in characteristics are pertinent to delivering customized learning scenarios. Such strategy of personalization combines different parameters to create a customized learning for every student. Researchers stressed on the consideration of the learners' level of knowledge that can lead to the promotion of personalized learning performance (e.g. Chen \& Duh, 2008; Henze et al., 2004; Jovanovic et al., 2009). Hence, the learner's ability significantly affects personalization. A personalized e-learning system was proposed by Chen et al. (2005) using item response theory that furnishes such a system based on the difficulty parameters attributed to the response of learners and the course materials provided (Chen et al., 2005). In the context of customary education, personalization refers to teaching and learning performance that entails the individual student's characteristics coupled with his requirements, practice and interaction in the quest to develop a constructive learning environment. The relevant processes include learning, matching and evaluation. It begins with collection of data among students (direct and indirect) with regards to their demographics and interaction during the process of learning (Chen \& Chung, 2008).

\subsection{Learning Community of E-learning}

A learning community refers to a group of people following the same learning strategy. Over time, changes in learning strategies were brought about by the development in technology and the internet, which brought about online learning an approach attributed with different learning patterns. The learning community comprise of individuals hailing from different places and backgrounds with the similar aim of learning common subjects.

According to Rovai (2002), learning needs can be satisfied by the online learning communities if they pursue a common goal that is supported by interaction through the system interface. Different interactive media necessitates the support of system learning, where the needs and characteristics of learners are considered when developing online courses (Dede, 1996). Several courses are offered online to motivate student participation in expanding the learning timings. Many authors have examined the inclination of students to adopt e-learning system via technology acceptance 
model (TAM). To this end, Pituch and Lee (2006) described the e-learning community as the unit of the virtual community that is created through the interaction of individuals having a common interest on the Internet. In other words, the online learning community comprises of students and system components.

\subsection{Perceived Usefulness, Perceived Ease of Use and Intention to Use E-learning}

Although several factors can affect the system, according to research, two major factors are top contributors namely perceived usefulness and perceived ease of use. The former is the use of an application to the level that the users are convinced that the application can improve their work performance while the latter is when the user is convinced that the application and the system are useful. In this context, the performance advantages are outweighed by the effort of application use and as such, the usage is significantly affected by the user's perceived ease of use. According to Davis (1989), behavioral intentions are significantly affected by attitude and both perceived usefulness and ease of use. Both variables also influence attitude towards use although perceive of use does not impact perceived usefulness.

In a related study, Selim (2007) determined users' behavioral intention with the help of the technology acceptance model (TAM) and he found satisfaction to be the answer for user's ongoing intention to use - such intention was determined by perceived usefulness, value of knowledge, confirmation, service quality, perceived ease of use and cognitive absorption (Selim, 2007). In case a user is utilizing a specific system, his beliefs of the affects on job performance can be used as a benchmark in measuring his perceived usefulness of the system. This in turn will affect his attitude in information system use. Lack of e-learning acceptance as a tool would lead to the oversight of its potential to improve education and training performance. Owing to the use of information technology in e-learning, TAM is considered to be appropriate in the e-learning context to be employed for students' acceptance evaluation in the context of a course website tool in the university (Selim, 2003). Moreover, the satisfaction of learners is also significantly affected by their computer anxiety, behavior of their instructors, flexibility and the quality in e-learning course and the evaluation types (Sun et al., 2000). Liew et al. (2007) contended that behavioral intention is influenced by perceived usefulness and selfefficacy and that with the improvement of e-learning quality, learners attitudes towards e-learning also improve. In comparison to the traditional offline education, the students' participation also increases. With the passing of time, web technologies improved providing the learners an opportunity to obtain knowledge with no cost included. The providers can also enhance the e-learning services.

Along the same line of study, Venkatesh and Davis (1996) concentrated on providing an insight into the antecedents of perceived ease of use and concluded that computer self-efficacy determines perceived ease of use prior to and following the hands-on use and that the objective appropriateness determines ease of use only following direct system experience. Meanwhile, Grandon, Alshare and Kwan (2005) stressed that e-learning self-efficacy indirectly affects the intentions of students via perceived ease of use. Added to the above studies, Mungania and Reio (2005) reported a significant dispositional barriers-e-learning self-efficacy relationship.

As proposed in TAM2, one of the social influence variables, namely subjective norm, is described as the perceived social pressure to carry out or refrain from carrying out a behavior (Ajzen, 1991). It appears significant to determine the way social influence impact the user's commitment to using IS in order to understand, explain, and predict system use and acceptance behavior (Malhotra \& Galleta, 1999). In a related study, Gradon, Alshare and Kwan (21005) referred to subjective norm as a significant factor that affects the intention of university students to make use of e-learning. Contrastingly, Ndubisi (2006) revealed that subjective norm had an insignificant effect on such intention.

\subsection{Self-efficacy of E-learning}

Self-efficacy is described as the individual's confidence level in performing a given task or achieving specific objectives. In the realm of education, self-efficacy is a concept that is related to the self-assessment of competence (Bandura, 1997) and in the context of web-based learning, internet self-efficacy has a key role in the identification of the intellectual understandings of students and their communication in their activities via the internet (Shu, 2008). The ISE reflects the poise and self-confident of the students in terms of operating the internet functions, where ISE positively influences online courses (Yukselturk and Bulut, 2007). Self-efficacy is also referred to as the opinion of people concerning their reliability in the management and performance of an activity that needs their carrying out of a specific action not involving the skills they have but their judgment on what they are capable of doing with the skills they posses. Hence, self-efficacy can enhance behavior and association of support (Rosland et al., 2008). In this regard, Tsai and Tsai's (2003) internet selfefficacy scale was proposed. In such a scale, a modified questionnaire was developed consisting of three primary items that assess the matter in focus. Prior studies advocated that learners' self-efficacy can be enhanced through the 
improvement of the learner's social support, which in turn, will assist changes in behavior (Fiori et al., 2006).

\subsection{Students' Satisfaction of E-learning}

Wang (2009) analyzed adult respondents in a research to shed a light on students' satisfaction of e-learning and his findings highlighted four major factors namely personalization, content, learning community and learners' interface. According to Lu and Choiu (2010), in order to examine the relationship between the above four factors and students' satisfaction of e-learning, it is important to examine their impact on three contingent variables (sex, career status and learning pattern) towards the relationship between predictors and e-learning system satisfaction. The last two variables showed significant effects on the relationship.

Owing to the fact that satisfaction with an educational product or service results from the interaction between instructors and students, research dedicated to satisfaction developed a comprehensive model (Yi, 1990) that explains the constructs and their interrelationships (antecedents and satisfaction outcome). To this end, Giese and Gote (2000) brought forward a definition framework explaining consumer satisfaction that could minimize the gap in literature. In relation to this, Malik (2010) reported that technical facilitation, students and instructors' behavior, computer efficiency, teacher's response during e-learning and a user-friendly interface all form the main factors in the students' satisfaction with web-learning. A comprehensive model and instrument to measure learner's satisfaction with e-learning systems was also proposed by Wang (2003).

\section{Research Methodology}

A suitable methodology can guide the process of developing a system that can be systematically managed and implemented. The present study employed a quantitative research design method where in 268 questionnaire sets were randomly distributed to the undergraduate students enrolled at the Faculty of Computing (FC) in Universiti Teknologi Malaysia. Data analysis was carried out through the SPSS application, Version 20 and Smart PLS. Specifically, the instrument utilized in this study was developed based on the study objectives, after which it was piloted and the Cronbach's alpha reliability and validity was found to be 0.852 . Such validity is acceptable and thus, the instrument was deemed to satisfy the reliability requirement. Also, a five-point likert scale with 1 depicting strongly disagree and 5 depicting strongly agree was employed in this study. The questionnaire was refined according to the results of the pilot study conducted among students. The questionnaire comprised of 27 items.

\section{Results and Discussion}

Table 1: Summary on using e-learning and e-learning contents

\begin{tabular}{|l|c|c|l|c|c|}
\hline \multirow{2}{*}{ Demographic Variables Category } & \multicolumn{2}{|c|}{ Research Sample (n=268) } & Demographic Variables Category & \multicolumn{2}{|c|}{ Research Sample(n=268) } \\
\cline { 2 - 6 } & Frequency & Percent & & Frequency & Percent \\
\hline Long of use & 7 & 3.0 & Time use on a day & 37 & 140 \\
Never & 70 & 26.0 & $1-2$ hours & 111 & 41.0 \\
1semester & 80 & 30.0 & $3-4$ hours & 67 & 25.0 \\
2 semesters & 20 & 7.0 & $5-6$ hours & 24 & 16.0 \\
3semesters & 19 & 7.0 & More than 6 hours & & 4.0 \\
4semesters & 72 & 27.0 & & & \\
More than 4 & 15 & 5.0 & Yes & 110 & 46.0 \\
\hline Time use on a week & 83 & 31.0 & No & 7 & 51.0 \\
Less than hour & 83 & 31.0 & Far & & 3.0 \\
1-2 times & 66 & 25.0 & & & \\
3-4 times & 21 & 8.0 & & \\
5 -6 times & &
\end{tabular}

It is also evident from the table (Table 4) that the percentage of respondents using e-learning services was $46 \%$, those who used e-learning before but are not currently using it constituted $51 \%$ of the total respondents and those who have yet to use e-learning constituted $3 \%$. The percentage of respondents based on their daily e-learning use is distributed as follows - $14 \%$ of respondents used e-learning daily, $41 \%$ used e-learning for an hour or two daily, $25 \%$ of the respondents used e-learning for 3-4 hours daily and $16 \%$ of them used e-learning for $5-6$ hours daily. Lastly, $4 \%$ of the respondents used the system for over 6 hours on a daily basis.

As for the weekly use of e-learning by respondents, according to Table $4,5 \%$ of the respondents used e-learning 
for less than hour weekly, 25\% used it from 5-6 hours weekly, $8 \%$ of them used e-learning for over 6 hours weekly and $31 \%$ used e-learning from 1-2 hours and from 3-4 hours.

With regards to the length of use, $3 \%$ of the respondents never used e-learning, $26 \%$ used it for 1 semester, $30 \%$ used it for 2 semesters, $7 \%$ for 3 semesters, and $7 \%$ for four semesters. Respondents who used e-learning for over 4 semesters constituted $27 \%$ of the total respondents.

\subsection{Measurement and Instrumentation}

The initial phase in confirming the validity and reliability of the measurement model is through the use of Partial Least Square Structural Equation Modeling (PLS-SEM), Smart PLS 3.0. Before the hypotheses are tested, two steps were conducted to establish the model's goodness-of-fit; first the construct validity test that includes the determination of factor loadings, composite reliability, Cronbach's alpha, and convergence validity. According to Fornell and Larcker (1981), the criterion test should be used to confirm discriminant validity. The tests are discussed in the following sub-sections in detail.

\subsection{Construct Validity of the Measurements}

Construct validity is considered as the level to which the items developed to measure a construct can suitably measure the concept they are intended to measure (Hair et al., 2010). It is important for the entire measures developed to measure a construct to load higher on their construct compared to other constructs. This was guaranteed through a thorough literature review of prior studies to identify items that whose reliability has already been established and tested. On the basis of the results of factor analysis, all items were appropriately assigned to their constructs as they revealed high loadings to their respective constructs in comparison to other constructs (See Table 2) according to the criterion proposed by Chow and Chan (2008).

Table 2: Loading and cross-loadings of the items

\begin{tabular}{|c|c|c|c|c|c|c|c|c|c|c|c|}
\hline No & Variables & Code & $C$ & IN & $P$ & $\mathrm{CL}$ & SE & PU & $\mathrm{PE}$ & IU & SS \\
\hline 1 & \multirow{4}{*}{ Content of E-Learning } & $\mathrm{C} 1$ & 0.798 & 0.372 & 0.418 & 0.374 & 0.319 & 0.321 & 0.312 & 0.250 & 0.314 \\
\hline 2 & & $\mathrm{C} 2$ & 0.833 & 0.360 & 0.362 & 0.354 & 0.272 & 0.263 & 0.254 & 0.203 & 0.311 \\
\hline 3 & & $\mathrm{C} 3$ & 0.816 & 0.316 & 0.286 & 0.298 & 0.227 & 0.168 & 0.207 & 0.135 & 0.253 \\
\hline 4 & & $\mathrm{C} 4$ & 0.737 & 0.345 & 0.277 & 0.338 & 0.262 & 0.201 & 0.284 & 0.247 & 0.371 \\
\hline 5 & \multirow[t]{5}{*}{ Interface of E-learning } & IN1 & 0.273 & 0.754 & 0.454 & 0.210 & 0.233 & 0.086 & 0.176 & 0.171 & 0.198 \\
\hline 6 & & $\mathrm{~N} 12$ & 0.330 & 0.831 & 0.460 & 0.270 & 0.224 & 0.161 & 0.250 & 0.190 & 0.255 \\
\hline 7 & & IN3 & 0.397 & 0.874 & 0.452 & 0.294 & 0.241 & 0.232 & 0.292 & 0.251 & 0.294 \\
\hline 8 & & IN4 & 0.353 & 0.821 & 0.421 & 0.292 & 0.236 & 0.245 & 0.292 & 0.298 & 0.307 \\
\hline 9 & & IN5 & 0.377 & 0.693 & 0.414 & 0.317 & 0.253 & 0.298 & 0.355 & 0.330 & 0.288 \\
\hline 10 & \multirow[t]{4}{*}{ Personalization } & P1 & 0.337 & 0.317 & 0.695 & 0.332 & 0.277 & 0.269 & 0.299 & 0.171 & 0.354 \\
\hline 11 & & P2 & 0.260 & 0.308 & 0.691 & 0.297 & 0.282 & 0.217 & 0.318 & 0.117 & 0.271 \\
\hline 12 & & P3 & 0.293 & 0.267 & 0.730 & 0.340 & 0.294 & 0.400 & 0.347 & 0.310 & 0.314 \\
\hline 13 & & P4 & 0.268 & 0.362 & 0.745 & 0.377 & 0.351 & 0.358 & 0.353 & 0.353 & 0.365 \\
\hline 14 & \multirow[t]{4}{*}{ Community } & CL1 & 0.345 & 0.282 & 0.366 & 0.771 & 0.386 & 0.441 & 0.349 & 0.202 & 0.441 \\
\hline 15 & & $\mathrm{CL2}$ & 0.375 & 0.269 & 0.341 & 0.801 & 0.397 & 0.390 & 0.396 & 0.254 & 0.394 \\
\hline 16 & & CL3 & 0.277 & 0.237 & 0.349 & 0.771 & 0.288 & 0.371 & 0.313 & 0.268 & 0.319 \\
\hline 17 & & CL4 & 0.307 & 0.284 & 0.388 & 0.692 & 0.392 & 0.353 & 0.263 & 0.301 & 0.306 \\
\hline 22 & \multirow[t]{3}{*}{ Self-Efficacy } & SE1 & 0.293 & 0.241 & 0.351 & 0.360 & 0.775 & 0.343 & 0.313 & 0.303 & 0.364 \\
\hline 23 & & SE2 & 0.288 & 0.244 & 0.291 & 0.348 & 0.845 & 0.274 & 0.279 & 0.289 & 0.351 \\
\hline 24 & & SE3 & 0.238 & 0.229 & 0.388 & 0.449 & 0.775 & 0.354 & 0.331 & 0.236 & 0.353 \\
\hline 25 & \multirow[t]{4}{*}{ Perceived Usefulness } & PU1 & 0.191 & 0.228 & 0.297 & 0.338 & 0.365 & 0.726 & 0.355 & 0.257 & 0.351 \\
\hline 26 & & PU2 & 0.241 & 0.224 & 0.309 & 0.344 & 0.277 & 0.777 & 0.327 & 0.337 & 0.308 \\
\hline 27 & & PU3 & 0.300 & 0.223 & 0.337 & 0.451 & 0.320 & 0.830 & 0.436 & 0.290 & 0.301 \\
\hline 28 & & PU4 & 0.196 & 0.152 & 0.335 & 0.441 & 0.287 & 0.736 & 0.464 & 0.313 & 0.254 \\
\hline 29 & \multirow[t]{4}{*}{ Perceived Easy to use } & PE1 & 0.251 & 0.241 & 0.318 & 0.329 & 0.210 & 0.432 & 0.717 & 0.275 & 0.255 \\
\hline 30 & & PE2 & 0.292 & 0.309 & 0.370 & 0.370 & 0.364 & 0.418 & 0.851 & 0.351 & 0.387 \\
\hline 31 & & PE3 & 0.252 & 0.293 & 0.400 & 0.328 & 0.336 & 0.394 & 0.830 & 0.326 & 0.314 \\
\hline 32 & & PE4 & 0.275 & 0.265 & 0.346 & 0.365 & 0.301 & 0.398 & 0.760 & 0.321 & 0.316 \\
\hline 33 & \multirow[t]{4}{*}{ Intention to Use } & IU1 & 0.214 & 0.366 & 0.354 & 0.308 & 0.285 & 0.295 & 0.247 & 0.684 & 0.291 \\
\hline 34 & & IU2 & 0.225 & 0.201 & 0.264 & 0.215 & 0.251 & 0.325 & 0.305 & 0.804 & 0.312 \\
\hline 35 & & IU3 & 0.186 & 0.248 & 0.192 & 0.215 & 0.255 & 0.282 & 0.325 & 0.764 & 0.253 \\
\hline 36 & & IU4 & 0.168 & 0.133 & 0.202 & 0.235 & 0.229 & 0.243 & 0.310 & 0.685 & 0.281 \\
\hline
\end{tabular}




\begin{tabular}{|l|l|l|l|l|l|l|l|l|l|l|l|}
\hline 37 & \multirow{3}{*}{ Students Satisfaction } & SS1 & 0.340 & 0.292 & 0.450 & 0.424 & 0.317 & 0.315 & 0.336 & 0.306 & 0.806 \\
\cline { 3 - 12 } & & SS2 & 0.265 & 0.225 & 0.317 & 0.373 & 0.353 & 0.270 & 0.291 & 0.310 & 0.824 \\
\cline { 3 - 11 } 39 & & SS3 & 0.338 & 0.292 & 0.306 & 0.355 & 0.387 & 0.344 & 0.326 & 0.298 & 0.732 \\
\hline
\end{tabular}

\subsection{Convergent Validity of the Measurements}

The values of composite reliability in Table 2 reveal that the values differ from 0.872-0.937, where they all exceeded the recommended value of 0.70 . Additionally, the values of Cronbach's alpha differ from 0.822 to 0.923 exceeding the recommended value of 0.70 , and the average variance extracted (AVE) values differ from 0.517 to 0.714 , all over the recommended value of 0.50 . The entire factor loadings are significant and exceeded 0.50 indicating that the recommendations provided by Fornell and Larcker (1981) and Hair et al. (2010) were satisfied. Table 3 also displays the CFA results for the measurement model.

Table 3: Convergent validity

\begin{tabular}{|c|c|c|c|c|c|c|}
\hline No & Variables & Code & Factors Loading & Cronbach's Alpha & Composite Reliability & AVE \\
\hline 1 & \multirow{4}{*}{ Content of E-Learning } & $\mathrm{C} 1$ & 0.798 & \multirow{4}{*}{0.809} & \multirow{4}{*}{0.874} & \multirow{4}{*}{0.635} \\
\hline 2 & & $\mathrm{C} 2$ & 0.833 & & & \\
\hline 3 & & C3 & 0.816 & & & \\
\hline 4 & & C4 & 0.737 & & & \\
\hline 5 & \multirow[t]{5}{*}{ Interface of E-learning } & IN1 & 0.754 & \multirow{5}{*}{0.856} & \multirow{5}{*}{0.896} & \multirow{5}{*}{0.636} \\
\hline 6 & & IN2 & 0.831 & & & \\
\hline 7 & & IN3 & 0.874 & & & \\
\hline 8 & & IN4 & 0.821 & & & \\
\hline 9 & & IN5 & 0.693 & & & \\
\hline 10 & \multirow[t]{4}{*}{ Personalization } & $\mathrm{P} 1$ & 0.695 & \multirow{4}{*}{0.688} & \multirow{4}{*}{0.800} & \multirow{4}{*}{0.500} \\
\hline 11 & & P2 & 0.691 & & & \\
\hline 12 & & P3 & 0.730 & & & \\
\hline 13 & & P4 & 0.745 & & & \\
\hline 14 & \multirow[t]{4}{*}{ Community } & CL1 & 0.771 & \multirow{4}{*}{0.758} & \multirow{4}{*}{0.845} & \multirow{4}{*}{0.577} \\
\hline 15 & & CL2 & 0.801 & & & \\
\hline 16 & & CL3 & 0.771 & & & \\
\hline 17 & & CL4 & 0.692 & & & \\
\hline 22 & \multirow[t]{3}{*}{ Self-Efficacy } & SE1 & 0.775 & \multirow{3}{*}{0.715} & \multirow{3}{*}{0.841} & \multirow{3}{*}{0.638} \\
\hline 23 & & SE2 & 0.845 & & & \\
\hline 24 & & SE3 & 0.775 & & & \\
\hline 25 & \multirow[t]{4}{*}{ Perceived Usefulness } & PU1 & 0.726 & \multirow{4}{*}{0.767} & \multirow{4}{*}{0.852} & \multirow{4}{*}{0.590} \\
\hline 26 & & PU2 & 0.777 & & & \\
\hline 27 & & PU3 & 0.830 & & & \\
\hline 28 & & PU4 & 0.736 & & & \\
\hline 29 & \multirow[t]{4}{*}{ Perceived Easy to use } & PE1 & 0.717 & \multirow{4}{*}{0.799} & \multirow{4}{*}{0.870} & \multirow{4}{*}{0.626} \\
\hline 30 & & PE2 & 0.851 & & & \\
\hline 31 & & PE3 & 0.830 & & & \\
\hline 32 & & PE4 & 0.760 & & & \\
\hline 33 & Intention to Use & IU1 & 0.684 & & & \\
\hline 34 & & IU2 & 0.804 & 0715 & 0.825 & 0.542 \\
\hline 35 & & IU3 & 0.764 & & & \\
\hline 36 & & IU4 & 0.685 & & & \\
\hline 37 & Students Satisfaction & SS1 & 0.806 & & & \\
\hline 38 & & SS2 & 0.824 & 0.694 & 0.831 & 0.621 \\
\hline 39 & & SS3 & 0.732 & & & \\
\hline
\end{tabular}

\subsection{Discriminant Validity of the Measures}

Discriminant validity is a test that assesses the level to which a concept and its indicators vary from one concept to the next (Bagozzi et al., 1991). The AVE values result showed that all the values exceeded the 0.50 recommended value with $p=0.001$, indicating that discriminant validity is supported for the entire constructs (Fornell \& Larcker, 1981). In relation to this, Hair et al. (2010) stated that the items correlations in any two constructs should not exceed the square root of the average variance shared by them within a single construct (See Table 4). 
Table 4: Discriminant validity

\begin{tabular}{|c|c|c|c|c|c|c|c|c|c|}
\hline & $\mathrm{CL}$ & $\mathrm{C}$ & $\mathrm{IU}$ & $\mathrm{IN}$ & $\mathrm{PE}$ & $\mathrm{PU}$ & $\mathrm{P}$ & $\mathrm{SE}$ & $\mathrm{SS}$ \\
\hline $\mathrm{CL}$ & 0.760 & & & & & & & & \\
\hline $\mathrm{C}$ & 0.433 & 0.797 & & & & & & & \\
\hline $\mathrm{IU}$ & 0.329 & 0.270 & 0.736 & & & & & & \\
\hline $\mathrm{IN}$ & 0.353 & 0.441 & 0.320 & 0.797 & & & & & \\
\hline $\mathrm{PE}$ & 0.441 & 0.339 & 0.404 & 0.352 & 0.791 & & & & \\
\hline $\mathrm{PU}$ & 0.516 & 0.303 & 0.390 & 0.268 & 0.518 & 0.768 & & & \\
\hline $\mathrm{P}$ & 0.473 & 0.423 & 0.344 & 0.550 & 0.454 & 0.417 & 0.671 & & \\
\hline $\mathrm{SE}$ & 0.484 & 0.343 & 0.346 & 0.299 & 0.385 & 0.406 & 0.430 & 0.799 & \\
\hline $\mathrm{SS}$ & 0.489 & 0.401 & 0.387 & 0.344 & 0.405 & 0.394 & 0.459 & 0.447 & 0.788 \\
\hline
\end{tabular}

\subsection{Analysis of the Structural Model}

Following the establishment of the measurement model's goodness of fit, the next phase involved the testing of the hypothesized relationships among the constructs and this is carried out through Smart PLS 3.0, specifically through the PLS algorithm. In this test, the path coefficients were produced as displayed in Figures 1 based on the illustrations in Figures 2, 3 and Table 4.

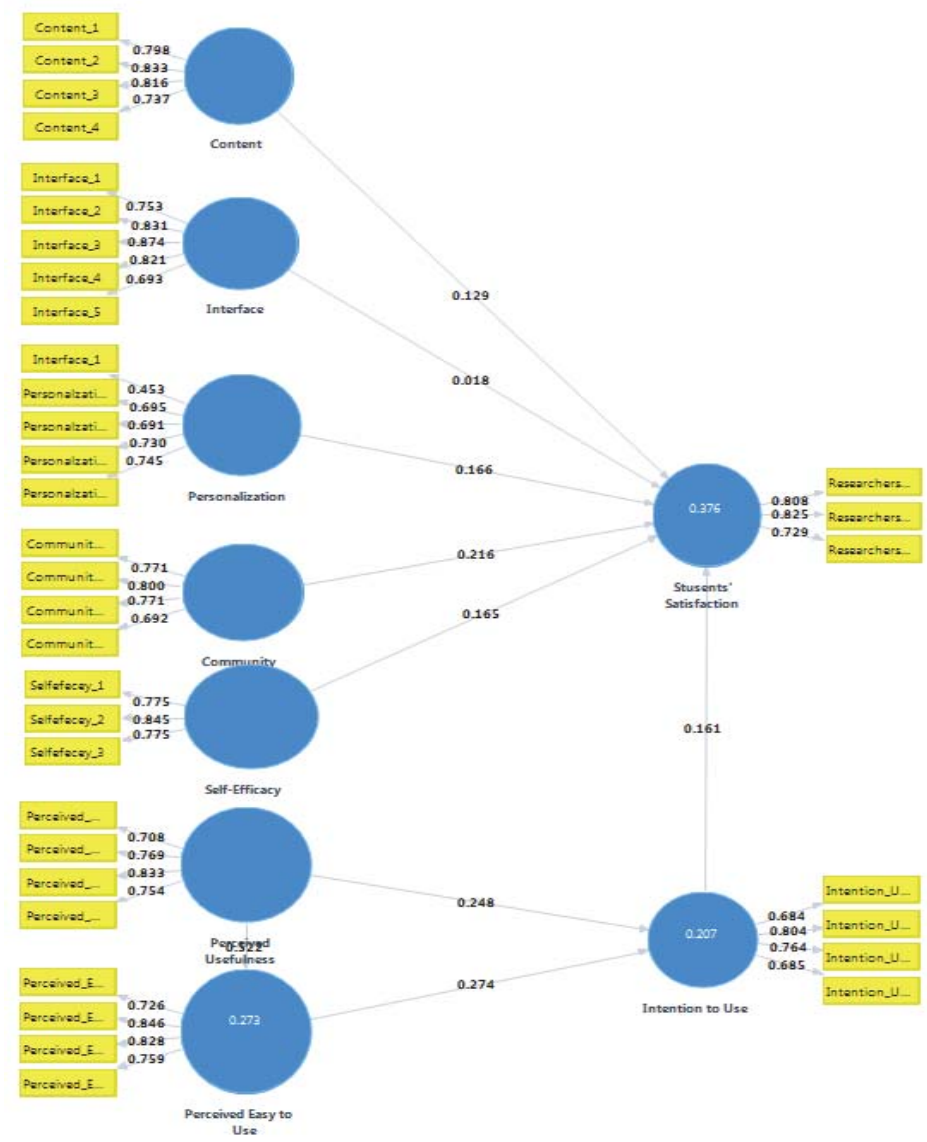

Figure 2: Path Coefficients Results 


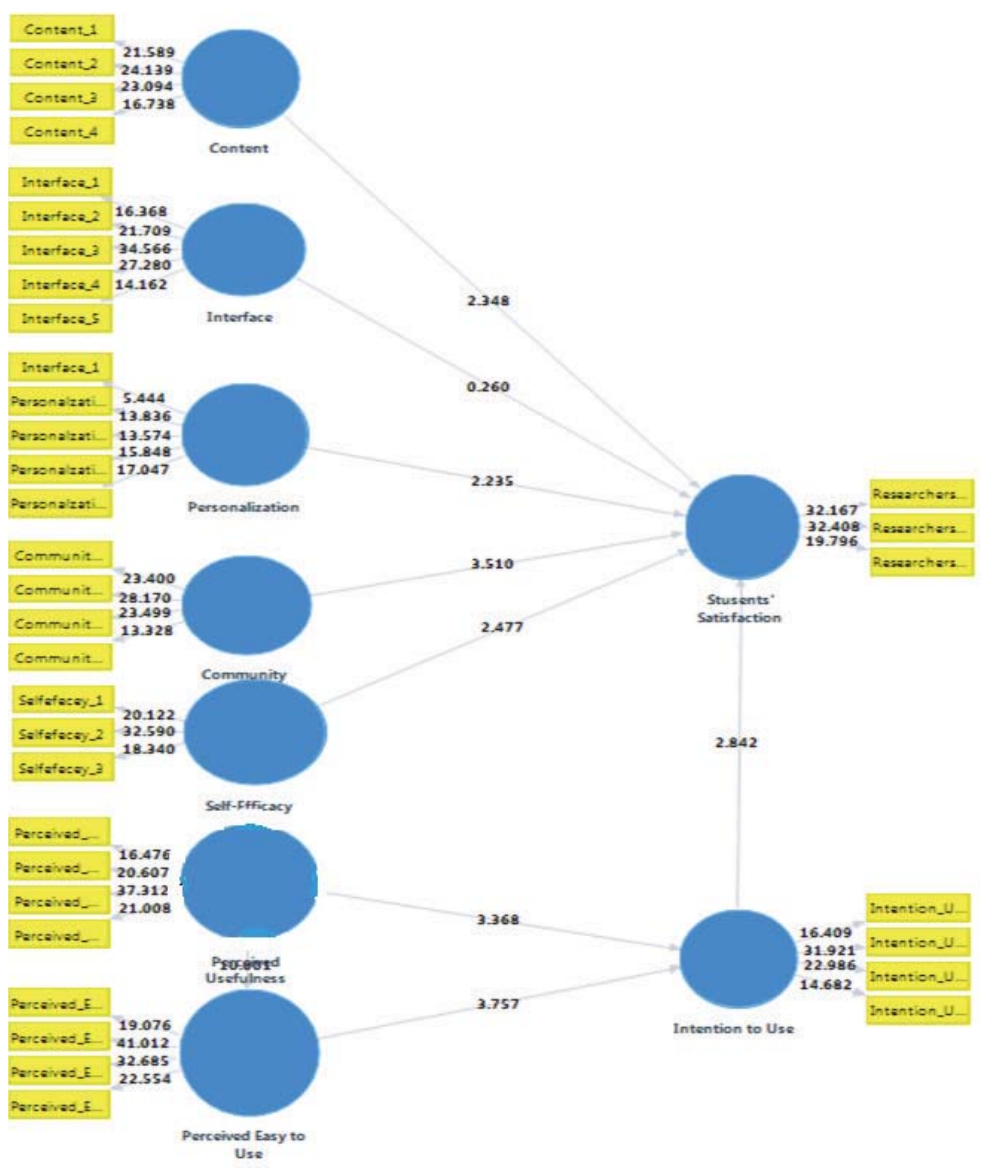

Figure 3: Path Coefficients T Values

Table 5: Hypotheses testing

\begin{tabular}{|l|c|c|c|c|c|c|l|l|}
\hline H & Independent & Relationship & Dependent & Path coffecent & Standard Error & T Value & P Value & Result \\
\hline H1 & C & $\longrightarrow$ & SS & 0.129 & 0.055 & 2.348 & 0.019 & Supported \\
\hline H2 & IN & $\longrightarrow$ & SS & 0.018 & 0.070 & 0.260 & 0.795 & Unsupported \\
\hline H3 & P & $\longrightarrow$ & SS & 0.166 & 0.074 & 2.235 & 0.026 & Supported \\
\hline H4 & CL & $\longrightarrow$ & SS & 0.216 & 0.062 & 3.510 & 0.000 & Supported \\
\hline H5 & SE & $\longrightarrow$ & SS & 0.165 & 0.067 & 2.477 & 0.014 & Supported \\
\hline H6 & PU & $\longrightarrow$ & IU & 0.248 & 0.074 & 3.368 & 0.001 & Supported \\
\hline H7 & PE & $\longrightarrow$ & IU & 0.274 & 0.073 & 3.757 & 0.000 & Supported \\
\hline H8 & IU & $\longrightarrow$ & SS & 0.161 & 0.057 & 2.842 & 0.005 & Supported \\
\hline H9 & PU & $\longrightarrow$ & PE & 0.522 & 0.052 & 10.001 & 0.000 & Supported \\
\hline
\end{tabular}

The study results supported eight study hypotheses and rejected one. The detailed discussion in provided in this section. In particular, the results revealed that e-learning content positively and significantly influenced students' satisfaction with e-learning at $(\beta=0.129, t=2.348, p<0.001)$ and this indicates support for the first hypothesis that contended a significant relationship between the two variables. The results also showed that e-learning interface was not positively and 
significantly related to students' e-learning satisfaction at $(\beta=0.018, t=0.260, p<0.001)$ indicating the rejection of the second hypothesis that stated a negative relationship between the two variables. The results showed a significant relationship between e-learning personalization and students' e-learning satisfaction at $(\beta=0.166, t=2.235, p<0.001))$ and this shows support for the third hypothesis. Moreover, according to the results, e-learning community positively and significantly influenced e-learning satisfaction of students at $(\beta=0.216, t=3.510, p<0.001)$ indicating support for the fourth hypothesis that stated a significant relationship between e-learning community and e-learning satisfaction of students.

The fifth hypothesis proposed that e-learning self-efficacy positively and significantly influenced the e-learning satisfaction of students and the results supported this contention at $(\beta=0.165, t=2.477, p<0.001)$. The sixth hypothesis was also supported by the results, which showed a positive and significant relationship between perceived usefulness of e-learning and intention to use e-learning at $(\beta=0.248, t=3.368, p<0.001)$. Moving on to the seventh proposed hypothesis, which proposed a positive and significant relationship between perceived ease of use of e-learning and intention to use e-learning - this is supported by the results at $(\beta=0.274, t=3.757, p<0.001)$. Hypothesis eight proposes a positive and significant relationship between intention to use e-learning and students' satisfaction of e-learning and this is supported at $(\beta=0.161, t=2.842, \quad p<0.001)$.Finally, hypothesis nine proposed a positive and significant relationship between perceived usefulness and perceived ease of use of e-learning and this is supported by the results ( $\beta=0.522$, $t=10.001, p<0.001)$. The entire results supported the use of TAM model in the examination of e-learning use in Malaysian higher education institutions.

\subsection{Discussions}

According to this study's results, students perceive high levels of relationship between e-learning content, e-learning personalization, e-learning community, and e-learning self-efficacy with e-learning satisfaction but such a relationship was rejected in terms of e-learning interface. The detailed relationships are discussed in this section. Both perceived usefulness and perceived ease of use relates to e-learning indicating that the students perceive the e-learning system to be useful. The results supported a relationship between perceived ease of use of e-learning and students' intention to use it, and between perceived usefulness of e-learning and intention to use it. The results also supported a relationship between e-learning community and e-learning satisfaction among students. The four relationships above obtained average to acceptable values in terms of students' satisfaction while user interface of e-learning obtained unacceptable values.

In light of the above, the researcher recommends that e-learning interface is updated to align it with new technology as this will provide the students with the inclination to use the system in their learning at any time and any place.

\section{Conclusion and Future Works}

The present study supported the contention that TAM is effective to use as a theoretical model to understand and shed light on behavioral intention to use e-learning. The present study's results led the researcher to conclude that the model well represents the data collected based on its goodness-of-fit. In the field of e-learning, no study has been conducted to identify the factors causing students' satisfaction with e-learning. Therefore, the present study highlighted such factors in the context of Malaysian higher education institutions. The findings revealed enhancement of students' perceptions of elearning and their satisfaction. For future studies, it is recommended that authors include other factors that align with the educational environment, in terms of the barriers of integrating instructional technology into higher education in various countries. Such factors include technology infrastructure, effort expended by the faculty, satisfaction with the technology and the competency of graduates.

\section{Acknowledgment}

This material is based upon work supported by Instructional Development Grant (IDG) and Research University Grant (RUG) Universiti Teknologi Malaysia, and the Academy of Sciences for the Development World (TWAS) Research Grant under Vote No. 08216,02J 57, and 10-147 RG/ITC/AS_C; UNESCO FR:3240246311. Any opinions, findings, and conclusions or recommendations expressed in this material are those from the authors and do not necessarily reflect on the views of the Universiti Teknologi Malaysia and the Academy of Sciences for the Development World; also supported by Faculty of Marine, Hodeidah University, Hodeidah, Yemen. 


\section{References}

Ajzen, I. (1991). The theory of planned behavior. Organizational Behavior and Human Decision Processes, 50, $179-211$.

Bagozzi, R.P., Davis, F.D., and Warshaw, P.R. (1992). Extrinsic and intrinsic motivation to use computers in the workplace. Journal of Applied Social Psychology, 22(14), 111-1132

Bandura, A. (1977). Self-efficacy: Toward a Unifying Theory of Behavioral Change. Psychological Review (84:2), February, pp. $191-215$.

Chen, C.-M. (2008). Intelligent web-based learning system with personalized learning path guidance. Computers \& Education, 51(2), 787-814

Chen, C.-M., Lee, H.-M., and Chen, Y.-H. (2005). Personalised e-learning system using item response theory. Computers \& Education, 44(3), 237-255.

Chen, C.-M., and Chung, C.-J. (2008). Personalized mobile English vocabulary learning system based on item response theory and learning memory cycle. Computers \& Education 51(2), 624-647.

Chou, C. (2003). Interactivity and interactive functions in web-based learning systems: A technical framework for designers. British Journal of Educational Technology, 34(4), 265-279.

Coffman, M. (2008). Effects of tangible social support and depression on diabetes self-efficacy. Journal of Gerontological Nursing, 34(4), 32-39.

Giese, J.and Gote (2000).Defining consumer satisfaction, Academy of Marketing Science Review 00 (01)

Grandon, E., Alshare, O., \& Kwan, O. (2005). Factors influencing student intention to adopt online classes: A cross-cultural study. Journal of Computing Sciences in Colleges, 20(4), 46-56.

Davis, F et al., (1989). User Acceptance of Computer Technology: A Comparison of Two Theoretical Models .Management Science (35:8) , pp. 982-1 003.

Dede, C. (1996). The evolution of distance education: Emerging technologies and distributed learning. American Journal of Distance Education, 10(2), 4-36.

Fiori, K et al., (2006). Social relations and depressive symptomatology: Self-efficacy as a mediator. Aging \& Mental Health, 10(3), 227239.

Fornell, C., and Larcker, D. F. (1981). Evaluating structural equation models with unobservable variables and measurement error. Journal of Marketing Research, 39-50.

Hara, N. (2000). Student distress in a web-based distance education course. Information, Communication and Society, 3(4), 557-579.

Henze, N., Dolog, P., and Nejdl, W. (2004). Reasoning and Ontologies for Personalized E-Learning in the Semantic Web. Educational Technology \& Society, 7(4), 82-97.

Hong, K. (2002). Relationships between students' and instructional variables with satisfaction and learning from a Web-based course.Internet and Higher Education, 5, pp. 267-281

Jovanovic, J., Gasevic, D., and Devedzic, V. (2009). TANGRAM for Personalized Learning Using the Semantic Web Technologies. Journal of Emerging Technologies in Web Intelligence, 1(1), 6-21.

Koohang, A., and Durante, A. (2003). Learners' perceptions toward the web-based distance learning activities/assignments portion of an undergraduate hybrid instructional model. Journal of Informational Technology Education, 2, 105-113.

Kilmurray, J. (2003). E-learning: It's more than automation. The Technology Source archives.

Lee, M. et al., (2005). Acceptance of internet-based learning medium: The role of extrinsic and intrinsic motivation. Information and Management, 42, 1095-1104.

Leem, J., and Lim, B. (2007). The current status of e-learning and strategies to enhance educational competitiveness in Korean higher education. The International Review of Research in Open and Distance Learning, 8(1).

Liaw, S. (2008).Investigating students' perceived satisfaction, behavioral intention, and effectiveness of e-learning: A case study of the Blackboard system. Computers \& Education, 51, 864-873.

Liaw, et al., (2007). An activity-theoretical approach to investigate learners' factors toward e-learning systems. Computers in Human Behavior, 22(4), 1906-1920.

Lu, H. and Chiou, M. (2010). The impact of individual differences on e-learning system satisfaction: A contingency approach.British Journal of Educational Technology, 41, 2, pp. 307.323.

Malik, M. (2010) .Factor Effecting Learner's Satisfaction Towards E-Learning: A Conceptual Framework. OIDA International Journal of Sustainable Development, 2, 3, pp. 77-82.

Malhotra, Y., and Galletta, D. F. (1999). Extending the technology acceptance model to account for social influence: Theoretical bases and empirical validation. Proceedings of the 32nd Hawaii International Conference on System Sciences, 1999.

Mungania, P., and Reio, Jr. T. G. (2005). If e-learners get there, will they stay? The role of e-learning self-efficacy. Eric ed492287. Paper presented at the Academy of Human Resource Development International Conference (AHRD), Estes Park, CO, Feb 24- 27, 2005, p. 1110-1117 (Symp. 48-2).

Ndubisi, N. O. (2006). Factors of online learning adoption: A comparative juxtaposition of the theory of planned behavior and the technology acceptance model. International Journal on E-Learning, 5(4), 571-591.

Ong, C. and Lai, J. (2006). Gender differences in perceptions and relationships among dominants of e-learning acceptance. Computers in Human Behavior, 22(5), 816-829.

Piccoli, G. et al., (2001). Web-based virtual learning environments: a research framework and a preliminary assessment of effectiveness in basic IT skill training. MIS Quarterly, 25(4), 401-426. 
Pituch, K and Lee, Y. (2006). The influence of system characteristics on e-learning use. Computers and Education, 47(2), 222-244.

Rosland, A et al., (2008). When is social support important? The association of family support and professionalsupport with specific diabetes self-management behaviors. Journal of General Internal Medicine, 23(12), 1992-1999.

Rovai, A. (2004). A constructivist approach to online college learning. The Internet and Higher Education, 7(2), 79-93.

Rovai, A. (2002). Sense of community, perceived cognitive learning, and persistence in asynchronous learning networks. Internet and Higher Education, 5, 312.

Rudy, H. (2007). Summary report, EDUCAUSE core data service. 2009.

Saade, R. G. (2003). Web-based education information system for enhanced learning, EISL: Student assessment. Journal of Information Technology Education, 2, 267-277.

Saade, R and Otrakji, C (2007). First impressions last a lifetime: Effects of interface type on disorientation and cognitive load. Computers in Human Behavior, 23.

Selim, H. (2007). E-learning critical success factors: An exploratory investigation of student perceptions. International Journal of Technology Marketing, 2(2),

Selim, H. (2003). An empirical investigation of student acceptance of course websites. Computers and Education, 40(4), 343-360.

Shu-Sheng, L. (2008).Investigating students' perceived satisfaction, behavioral intention, and effectiveness of e-learning: A case study of the Blackboard system. Computers \&amp; Education, 2008. 51(2): p. 864-873.

Sun, et al., (2008). What drives a successful e-Learning? An empirical investigation of the critical factors influencing learner satisfaction. Computers \& Education, 50, 1183- P1202.

Tsai, M. and Tsai, C. (2003). Information searching strategies in web-based science learning: The role of Internet self-efficacy. Innovations in Education and Teaching International, 40, 43.50.

Yi,Y .(1990). A critical review of consumer satisfaction, in: V.A. Zeithaml (Ed.), Review of Marketing, American Marketing Association, Chicago, 1990, pp. 68-123.

Yi, M., and Hwang, Y. (2003). Predicting the use of web-based information systems: Self-efficacy, enjoyment, learning goal orientation, and the technology acceptance model. International Journal of Human-Computer Studies, 59, 431-449.

Yukselturk, E, and Bulut, S. (2007). Predictors for student success in an online course. Educational Technology \& Society, 10(2), 71-83.

Venkatesh, V., and Davis, F. D. (1996). A model of the antecedents of perceived ease of use: Development and test. Decision Sciences, 27, 451-481.

Wang, Y. (2003). Assessment of learner satisfaction with asynchronous electronic learning systems. Information \& Management, $41,75-$ 86.

Wang, $Y$ and Yang, C. (2005). The interface design and the usability testing of a fossilization web-based learning environment. Journal of Science Education and Technology, 14(3), 305-313. 